\title{
QuATRO DÉCADAS DE PESQUisAs EM ARQUiTETURA: SISTEMATIZAÇÃO E REFLEXÃO
}

\author{
Mônica Junqueira de Camargo
}

O curso de pós-graduação em Arquitetura e Urbanismo da FAUUSP está comemorando 40 anos, um marco que não pode passar desapercebido, dado o significado dessa trajetória para a consolidação do conhecimento na área da arquitetura, do urbanismo e do design no Brasil. São mais de dois mil trabalhos entre mestrados (1217) e doutorados (808), disponíveis para consulta na biblioteca, grande parte deles, inclusive, online. Seus egressos integram o corpo docente das principais universidades do País, muitos ocupando lugar de destaque na administração pública e nos mais diversos setores do desenvolvimento.

A trajetória de pesquisa da FAUUSP remonta à autonomia do curso de arquitetura em relação à Escola Politécnica, em 1949, com a abertura de muitas frentes de investigação que a criação da Pós constituiu um passo decisivo para sua organização e sistematização. O Programa de Pós-Graduação da FAUUSP foi criado como curso a partir da portaria GR 1442, de 01.04.71, mas sua efetiva consolidação se deu a partir de 1972, com a titulação de 16 doutores, ainda segundo os procedimentos da USP anteriores, que previam apenas a apresentação da tese. A partir de então constituiu-se como curso regular e a primeira turma de mestrado teve início em 1973. 0 curso de doutorado teve sua primeira turma em 1980, permanecendo como único doutorado em arquitetura e urbanismo no País até 1998.

De uma ampla e única área de Concentração Estruturas Ambientais Urbanas, em 2002, foram criadas oito áreas, com base na diversidade de assuntos (áreas) e de temas pesquisados, e na premência de alguns problemas daquele momento: Design e arquitetura; Hábitat; História e fundamentos da arquitetura e do urbanismo; Paisagem e ambiente; Planejamento urbano e regional; Projeto da arquitetura; Projeto, espaço e cultura; e Tecnologia da arquitetura, cujas fronteiras algumas vezes se sobrepõem, dada a interdisciplinariedade própria da arquitetura e do urbanismo.

O caráter crítico e investigativo necessários à produção do conhecimento e a responsabilidade frente ao seu papel de referência nacional impõem à Pós da FAUUSP permanente atualização. A estrutura que hoje apresenta é fruto de um paulatino processo de construção envolvendo escolhas, decisões e experimentações, cuja notoriedade reforça o compromisso de contínua revisão. O sistema de pósgraduação no País vem em uma progressiva dinâmica de ampliação, contando hoje com 28 programas credenciados (dos quais 15 incluem o doutorado), em um total de 22 instituições. Novas alternativas surgiram, inclusive de cursos oferecidos em parceria. Já há turmas formadas da parceria FAUUSP - UEL Universidade Estadual de Londrina (mestrado) e UFCE - Universidade Federal do Ceará (mestrado e doutorado).

O crescimento dos cursos de graduação no País e dos convênios com instituições estrangeiras tem ampliado a procura e diversificado o perfil dos pesquisadores, que requerem uma definição precisa do caráter dos vários cursos de pós-graduação. Os desafios das cidades do século 21, em um planeta que se urbaniza e apresenta o predomínio, pela primeira vez na história da população urbana, são muitos. As tensões inerentes a essa complexidade e ao contínuo processo de transformação decorrente da própria vitalidade dos centros urbanos exigem da arquitetura, do urbanismo e do design a constante reinvenção, à qual a academia deve contribuir antecipando questões e problematizando o panorama estabelecido.

A experiência do professor Francisco Spadoni, "L'isola Nascosta: A Ilha Oculta, projeto premiado em 10 Lugar no Wave 2011 / Workshop di Architettura di Venezia", que abre esta edição, é ilustrativa da presença brasileira no debate internacional. Foram 30 workshops de 30 arquitetos convidados que trabalharam o tema urban regeneration, tendo como foco Veneza e o Vêneto. A proposta de Spadoni refere-se às áreas das ilhas de Sacca Fisola e Sacca San Biagio, à espera de transformação, na qual trata de questões como lixo, recuperação ambiental, novas arquiteturas infraestruturais, e transposição e conexão entre ilhas.

Os dez artigos científicos desta edição revelam a diversidade das pesquisas acadêmicas no País e, as cinco resenhas, o dinamismo editorial da área, enquanto os eventos e as conferências confirmam a extensão dos trabalhos da pós-graduação e sua internacionalização. 
A análise de Vladimir Bartalini sobre o bairro Jardim Felicidade, no artigo intitulado "Brejos, vielas, escadas: um bairro-jardim e suas águas", resgata rica documentação do projeto do urbanista Jorge de Macedo Vieira e das condições atuais desse bairrojardim, cujas áreas livres especialmente aquelas com presença da água foram sendo transformadas, pouco restando de suas evidências.

As relações entre a arquitetura e a cidade de São Paulo são abordadas sob distintos enfoques nos três artigos seguintes. Em "O real panorama da polis: conflitos na produção do espaço em favelas localizadas em bairros de elite de São Paulo", Tiarajú D'Andrea, a partir de três eventos, constata o processo de expulsão das classes populares de áreas centrais da metrópole por meio da coerção econômica, viabilizada pela privatização da gestão urbana.

Felipe Anitelli e Marcelo Tramontano analisam, no artigo "Edifícios de apartamentos, São Paulo, anos 1950: mercado imobiliário e (um pouco de) arquitetura", as mudanças na produção de edifícios de apartamentos na cidade de São Paulo, a partir do surgimento do incorporador imobiliário nos anos 40. O período analisado concentra-se entre a lei da promulgação do inquilinato em 1942 e a fundação do Banco Nacional de Habitação (BNH) em 1964, quando se verificou a crescente profissionalização dos agentes imobiliários e a busca de empreendimentos mais baratos que levaram a uma padronização do projeto arquitetônico.

A partir da análise da legislação existente, dos aspectos urbanos e morfológicos da região central da cidade de São Paulo e dos projetos arquitetônicos dos anos 30 a 60 Sabrina Studart Fontenele Costa investiga a relação entre o surgimento dos arranhacéus modernos e as intervenções urbanas desse período, cuja escala permitiu o aparecimento de novos partidos arquitetônicos. Com especial atenção ao desenho do térreo, a autora analisa a interferência dos arranha-céus na transformação da área central, por meio da permeabilidade de suas plantas, da facilidade de acesso aos seus interiores e da disposição do programa arquitetônico cujos resultados são expostos no artigo intitulado "Continuidade e permeabilidade urbana nos arranha-céus modernos do Centro de São Paulo".

Corroborando a presença da preservação como tema de investigação, o artigo "Teoria e método no campo da restauração", de Claudia dos Reis e Cunha, apresenta a importância das questões teóricas para as intervenções de restauro, tanto para o reconhecimento do bem cultural como para a definição de uma metodologia adequada à sua preservação, uma vez que o restauro é um problema, não somente técnico, mas, sobretudo, históricocrítico. Enquanto Antonio José Faria Góis investiga a utilização da pedra no período colonial, especialmente o seu emprego, além da alvenaria e cantaria. No artigo "São Francisco e os caminhos da pedra" o autor expõe a ampliação e valorização do lioz nas obras complementares da arquitetura, tomando como estudo de caso os elementos que integram o conjunto conventual de São Francisco e o edifício anexo da Irmandade da Ordem Terceira, em Salvador.

O artigo "Bratke e o projeto civilizatório da Icomi", de Telma de Barros Correia, traz uma nova leitura sobre os projetos de Oswaldo Bratke para Serra do Navio e Vila Amazonas, da década de 1950.

Destacados pela historiografia, sobretudo pela racionalidade do empreendimento, pelos aspectos inovadores quanto ao conforto e adaptação ao clima, a autora reconhece nesses núcleos ainda um forte vínculo com os procedimentos usuais na história de núcleos fabris, os quais se revelam restritivos quanto à autonomia de seus moradores. A rígida divisão social do espaço, a segregação dos solteiros, a não concentração dos moradores nos espaços públicos, o controle do tempo livre e o combate ao ócio dos moradores estão entre os argumentos apontados pela autora que, válidos enquanto análise dos desenhos e memoriais, mas não da realidade que, de fato, constituiu-se nessas vilas.

A crescente atividade do turismo no País, especialmente diante da perspectiva de sediar os dois maiores eventos esportivos, a Copa do Mundo em 2014 e as Olimpíadas em 2016, coloca em pauta a necessidade de reflexão dessa atividade no contexto brasileiro, cuja trajetória é analisada no oportuno artigo "Da Embratur à política nacional de turismo", de Cristina Pereira de Araujo. A estruturação da atividade turística no Brasil, no âmbito das políticas públicas federais, segundo a autora, desenvolveu-se em três fases: Embratur nos anos 60; o Prodetur nos anos 90 e, já neste século, os Planos Nacionais de Turismo. A criação do Ministério do Turismo, em 2003, e a promulgação do Decreto n. 7.381, de 2 de dezembro de 2010, são indicadores que o turismo passou a ser entendido no Brasil como importante economia geradora de divisas, trabalho e renda. 0 impacto dessa atividade nas cidades brasileiras coloca-se como um grande desafio aos profissionais da arquitetura e do urbanismo. 
A partir do conto de Rudyard Kipling (18651936), Artur Simões Rozestraten tece considerações sobre as interações entre sacrifícios, cosmogonias arquitetônicas, arcaísmos e contemporaneidade. No artigo intitulado "Oferendas de construção: imaginário e tecnologia", o autor evidencia os vínculos históricos que afloram no processo contemporâneo de produção de arquiteturas e espaços urbanos, e que reafirmam a interação essencial entre tecnologia, poética e imaginário.

Por fim, a análise de uma proposta de ensino na Universidade de Córdoba, Argentina, nos anos 70, por Sylvia Adriana Dobry-Pronsato, resgata questões importantes para a o debate do ensino de arquitetura. 0 artigo "O Taller Total: uma experiência de ensino de arquitetura e urbanismo" analisa essa experiência argentina que revalorizava o pensamento da Bauhaus, com base em três premissas: a arquitetura como uma área de caráter prioritariamente social; seu ensino a partir da análise da sociedade e de suas necessidades; e sua gestão democrática e participativa.

Os seminários realizados no âmbito da disciplina AUH 5852 - Técnicas Construtivas Tradicionais e a Preservação de Edifícios Históricos, sob responsabilidade das professoras Beatriz Mugayar Kühl e Maria Lucia Bressan Pinheiro, publicados na seção Conferências, têm sido das contribuições mais frequentes para a revista Pós. A regularidade e a qualidade desses eventos, cujas comunicações esta revista tem o privilégio de publicar, já as estão qualificando como um acontecimento tradicional da área de Preservação, que tem atraído um público cada ano mais amplo. No segundo semestre do 2011, foram apresentadas quatro conferências dos convidados: Simona Salvo, João Mascarenhas Mateus, Claudia S. Rodrigues de Carvalho e Ascensión Hernández Martínez, que abordaram aspectos da preservação de bens culturais, com objetivo de discutir e aprofundar seus aspectos teóricometodológicos, para enfrentar os problemas projetuais e técnico-operacionais de intervenções nesses bens.

Na seção Eventos registramos o workshop "Biostructural analogies: arms, wings and mechanical things", com a participação do professor Anthony Viscardi, titular da Lehigh University (EUA), Department of Art, Achitecture, and Design, organizado pelos professores: Clice de Toledo Sanjar Mazzilli, Cibele Haddad Taralli e Artur Simões Rozestraten, baseou-se nas analogias bioestruturais como provocadoras do processo de projeto, buscando desenvolver objetos arquitetônicos cinéticos, flexíveis e articulados como sistemas. Os procedimentos tiveram como base os princípios de simulacro e analogia, utilizando como estímulo as aproximações comparativas entre asas, braços e máquinas com articulações e movimentos semelhantes. O workshop proporcionou uma situação peculiar de interação entre alunos, professores e técnicos, concentrados no mesmo propósito, compartilhando diariamente a dinâmica de desenvolvimento de colagens, desenhos e modelos tridimensionais, assim como as reflexões quanto à natureza e características dos processos projetuais. Constituiu-se, em suma, em uma ocasião oportuna para a reflexão sobre questões metodológicas, epistemológicas e sistêmicas, os processos de projeto e produção, temas que estão na pauta das discussões na área de concentração em Design e Arquitetura.

As resenhas revelam uma produção editorial de temas, abordagens e tempos diversos. Um ensaio sobre a casa brasileira do século XIX, de Solange de Aragão, obra resenhada por Carlos Lemos com o título "Um ensaio à espera de outro".

Ferrovias e Saneamento em São Paulo. O engenheiro Antonio Francisco de Paula Souza e a construção da rede de infraestrutura territorial e urbana paulista, 1870-1893, de Cristina de Campos, cuja resenha intitulada "Por uma história dos pioneiros da engenharia civil no Brasil", foi escrita por Beatriz Piccolotto Siqueira Bueno.

"Uma outra leitura da arquitetura moderna brasileira", de minha autoria, analisa o livro Brasil: arquiteturas após 1950, de Maria Alice Junqueira de Bastos e Ruth Verde Zein.

Chai-Na, de Otília Beatriz Fiori Arantes, foi analisada por Ruy Sardinha Lopes no texto "Um estudo sobre a era das formas urbanas extremas".

Higienópolis: grandeza de um bairro paulistano, a obra de Maria Cecília Naclério Homem, foi comentada por Mirandulina Maria Moreira Azevedo, sob o título "Entre memória e história: Higienópolis revisitado".

A revista conta também com o registro dos dez trabalhos defendidos no $2^{\circ}$ semestre de 2011.

Boa leitura.

Mônica Junqueira de Camargo

Editora-chefe

junqueira.monica@usp.br

rvposfau@usp.br

Tel.: (11) 3017-3164 